\title{
Induction Motor Drive Design based on Efficiency Optimization and Drive Loss Minimization in Real-time Control of Linkage Flux of Drive Reference
}

\author{
Farshid Abdolahnejad Baroogh ${ }^{1}$, Milad Gheydi ${ }^{2}$, Payam Farhadi ${ }^{3}$ \\ ${ }^{1}$ Department of Electrical Engineering, Semnan University, Semnan, Iran \\ ${ }^{2}$ Science and Research Branch, Islamic Azad University, Tehran, Iran \\ ${ }^{3}$ Parsabad Moghan Branch, Islamic Azad University, Parsabad, Iran
}

\begin{abstract}
Article Info
Article history:

Received Jun 7, 2017

Revised Aug 19, 2017

Accepted Aug 24, 2017

\section{Keyword:}

Control system.

Efficiency optimization

Induction motor

Linkage flux

Loss

ABSTRACT

Induction motor drives are commonly used for applications with vast variations in mechanical load for torques under nominal values. HVAC loads are among these loads. The most ideal scheme for induction motor drive design should include drive loss reduction, or efficiency improvement, proportional to load torque such that optimal performance of drive is not affected. In this paper, using analytical methods, an accurate model is proposed for induction motor drive design. This model allows us to utilize real control and classical control theory for better performance of drive control system. The most damaging mechanical load for induction motor drive is impulse load or so-called periodic load. A scheme proposed for power loss control includes loss control for this type of load, meanwhile, robustness of drive system and stator frequency stability are retained. Main advantages for this scheme are applicability and implementation on various induction motor drives with various powers, without any specific requirements and the least possible computation for the processors.
\end{abstract}

Copyright () 2017 Institute of Advanced Engineering and Science. All rights reserved.

\section{Corresponding Author:}

Milad Gheydi,

Science and Research Branch,

Islamic Azad University, Tehran, Iran

Email: gheydi.m@srbiau.org

\section{INTRODUCTION}

Electric production cost decrease is an important issue which is absorbed many attentions by electrical engineers. Electrical motors have a great contribution to electric power consumption. In practice, three-phase induction motors consume about $60 \%$ of industrial power demand [1], [2]. The ever-increasing growth of using induction motors in servo exciters led to great attention on transient torque-load profile characteristics. Thus, induction motor drives are important in terms of accuracy, efficiency control and low level of power loss. The efficiency increase and power loss reduction are not only important due to reduced power consumption and cooling convenience, but also they are vital for environmental pollution control. Power loss and efficiency of drive is a complex function of motor type, converter structure, type of semiconductor switches and converter modulation algorithm. Thus, control system is of importance in terms of efficiency and power loss [1], [3].

Nowadays, about one third of generated power all over the world is consumed by induction motors. Efficiency of this type of motor is varied significantly by motor mechanical load dynamics. A control strategy can, therefore, used to save huge amount of energy. Power loss in induction motor comprised of three components: copper loss of stator and rotor, core loss and mechanical loss. Due to induction motors' special design, core loss and copper loss are not well-balanced in non-nominal loads. This result in efficiency drop and power loss rise [4]. 
In converters supplying induction motors, optimal use of maximum converter current is of great importance from economic aspects. In low loads, this optimization requires motor performance to be in high torque to current rate (T/A). Thus, maximum output torque is obtained for mechanical load's fast acceleration. In many cases, loads with high torque amplitudes are employed on drive system iteratively. In such systems, converter current correction for specific flux and torque generation will be a dynamic issue. Machines with iterative processes are among this type of systems [3]. Major power loss in a converter composed of rectifier conduction loss, inverter conduction loss and inverter switching loss. Power loss related to the inverter is the main part among these power losses which is dependent on motor control strategy [5],[6]. Induction motor drive should, as a base role, appropriately react to output torque and/or speed variations considering design criteria. In most electric drives, especially in systems driving HVAC loads, drive works usually in low-load condition, leading engineers to design drive for optimizing efficiency and minimizing power loss [7]. One degree of freedom is available in drive control system by which one can influence power loss and efficiency. This degree of freedom is drive flux. Drive control systems often operate in fixed flux rates. Of course, considering the type of drive, its flux can be those of rotor, stator and air gap. In low load level, operation in nominal flux results in core loss increase and, in turn, drive efficiency decrease. Considering that drives operate mostly in loads under nominal value, thus, optimal efficiency can be achieved through planning on drive flux [1], [5]. In this regard [8]-[10] can be considered as the onset of research.

In this paper, contrary to the reported works in literature in this field, a power loss model for induction motor drive is proposed. This model is comprehensive and accurate comprising of all power loss related to flux in drive. Compared to the past research, this model can be implemented in control system in real-time. In addition, this model obviates computation time-consuming issue which was prevalent in past research [11]-[14]. The reason behind being less time-consuming is that this model does not need non-linear methods, including genetic algorithm (GA), artificial neural network (ANN), fuzzy systems and non-linear models reported in [15]. Past works [16]-[19] required especial requirements such as special inverter, special drive algorithm, special modulation, and etc. as initial conditions in order to implement power loss control algorithm. However, in this paper there exist no specific requirements and limitations of power and voltage for set of machine and converter. Here, power loss balance design is examined in terms of robustness. Analysis is done for all induction motor drives with desired power compared to some previous research [14].

\section{POWER LOSS REDUCTION BY FLUX LEVEL}

Principle of power loss reduction based on flux control is shown in Figure 1. Flux and current vectors diagram of induction motor are illustrated in loads under nominal load for three flux levels. In diagram-a, motor works in nominal flux where stator current is high while rotor current is low. Thus, core power loss and stator copper loss are high, however, rotor copper loss is low. In diagram-b, flux is decreased by $50 \%$, leading to twice the rotor current. This results in core loss decrease and rotor copper loss increase. As mentioned previously, induction motor design is done in a way that the operation is within saturation region. So, flux decrease in Figure1-b and reduction in motor magnetizing current, motor will exerted from this region, leading to remarkable decrease in flux and current of stator. Overall, further core loss decrease will be seen. Total power loss of motor in Figure 1-a is lower than that of in Figure 1-b. If motor flux is decrease further, core loss will be also decreased. However, rotor and stator copper losses increase, resulting in overall increased power loss. It can be concluded that for a specific load torque there exist an optimum flux level minimizing drive power loss. It should be noted that stator current increase means increased converter power loss. This will be proved in the next sections. If motor core loss is neglected, optimum flux level will be independent of speed. Optimum flux level is directly depending on the load torque [1], [5].
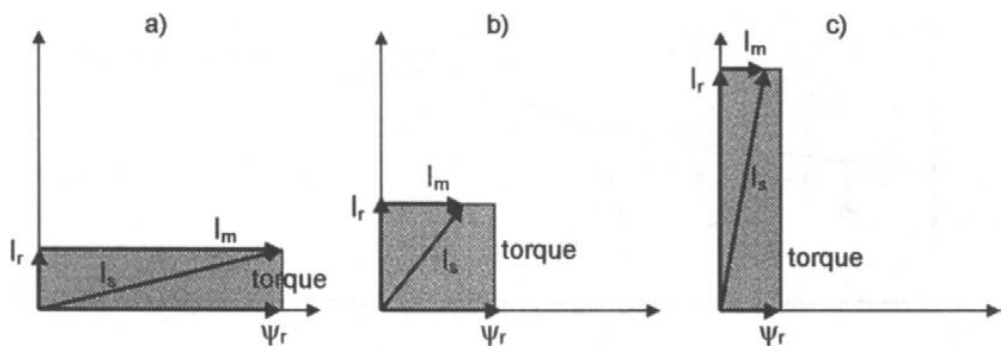

Figure 1. Flux and Current Vectors Diagram of Induction Motor in Under Nominal Load for Three Flux Levels. (a) Nominal, (b) Optimal, (c) Low. 


\section{EFFICIENCY AND POWER LOSS IN INDUCTION MOTOR} into four parts:

Power losses included in energy transmission from power system to mechanical load can be divided

a. Power system loss: Although rectifier has a power factor of unity, it absorbs harmonic currents resulting in power losses. This power loss is only affected by dc filter and power system performance and flux level has no effect on it.

b. Converter loss: In general, since converter loss is due to motor current, thus all power loss by converter is directly affected by drive flu level. In addition, other components such as modulation algorithm and load shifting ratio, motor power factor, have effect on this power loss.

c. Induction motor loss: Copper and core losses which are depended on flux level are main parts of power loss in induction motors. Other types of losses such as those related to windage and friction are negligible and independent of flux level. Thus, they are not considered in optimization or minimization process.

d. Mechanical loss: This type of power loss is related to mechanical energy transferring loads. The amount of this loss is negligible.

\section{MODELING CONVERTER LOSS}

As mentioned previously, converter loss is divided into two main parts: 1) rectifier conduction loss; 2) converter conduction and switching loss. Due to low level of leakage current in blocking condition, thud this condition can be ignored.

Considering structure of converters commonly used for induction motor drives, this paper assumes that the inverter is comprised of IGBT and rectifier is constituted of diode (see Figure (2)). However, combination of other semiconductors has no different results.

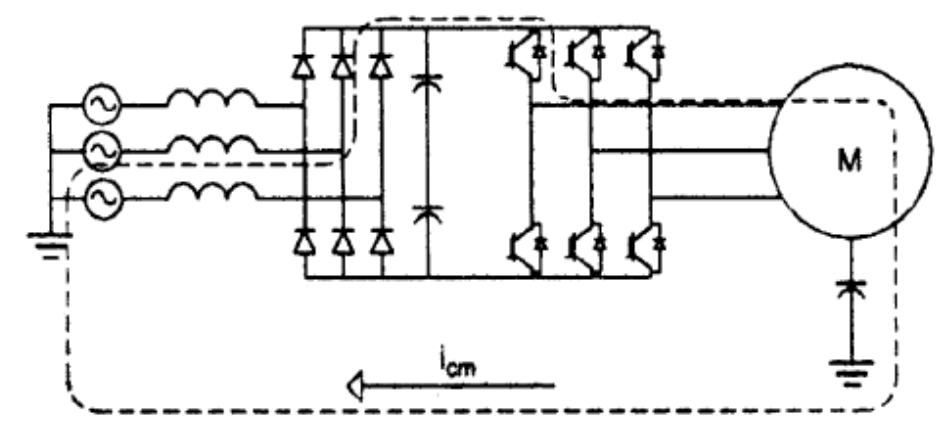

Figure 2. Structure of Converters Used for Induction Motor Drive

As the rectifier is only composed of power diodes, especial switching loss is not considered for it. Whereas, with IGBT, both switching and conduction losses are regarded for transistors and anti-parallel diodes. Overall, sum of conduction and switching losses for IGBT and diode is given by Equation. (1).

$$
\begin{aligned}
& P_{I G B T}^{C}=P_{\text {transistor }}^{c}+P_{A-p \text { diod }}^{c} \\
& P_{\text {Transistor }}^{c}=\frac{3}{\pi}\left(V_{c e} \cdot i_{s w}\left[1+\frac{m \pi \cos \varphi}{4}\right]+R_{d i f f}^{T} \cdot i_{s w}^{2}\left[\frac{\pi}{4}+\frac{2 m \cos \varphi}{3}\right]\right. \\
& P_{a-p \text { diod }}^{c}=\frac{3}{\pi}\left(V_{f} \cdot i_{s w}\left[1-\frac{m \pi \cos \varphi}{4}\right]+R_{d i f f}^{d} \cdot i_{s w}^{2}\left[\frac{\pi}{4}-\frac{2 m \cos \varphi}{3}\right]\right. \\
& P^{s w}=\frac{6 f_{s w} \cdot E_{s w} \cdot i_{s w}}{\pi}
\end{aligned}
$$


Where, $m$ is modulation index, $\cos \varphi$ is shifting factor or cosine of the angle between current first component and modulation reference wave, $R_{\text {diff }}$ is differential resistor across semiconductor and $V_{c e}, V_{f}$ is threshold voltage of semiconductor.

Equation. (1) implies that conduction loss is directly related to motor power factor, motor voltage level, modulation index, and motor current. Equation. (1) can be rewritten as Equation. (2).

For industrial IGBTs, it is assumed that $R_{\text {diff }}^{T} \cong R_{\text {diff }}^{d}$ and $V_{c e} \cong V_{f}$ can be valid.

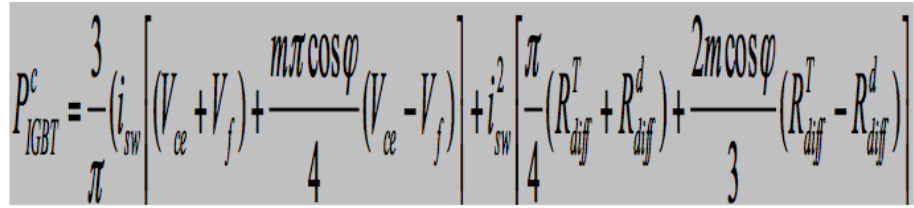

Thus power loss relations are simplified as Eq. (3)

$$
P_{I G B T}^{c}=\frac{3}{\pi}\left(2 \cdot i_{s w} \cdot V_{c e}+\frac{\pi}{2} \cdot i_{s w}^{2} \cdot R_{d i f f}\right)
$$

Summing up Equation. (3) and switching loss relation leads to inverter par loss in the converter. Since the rectifier is not controlled, thus power factor is close to unity working in maximum modulation index. Therefore, rectifier conduction loss is obtained by Equation. (4).

$$
P_{\text {diod }}^{c}=\frac{3}{\pi}\left(V_{f} \cdot i_{s w}\left[1-\frac{\pi}{4}\right]+R_{d i f f}^{d} \cdot i_{s w}^{2}\left[\frac{\pi}{4}-\frac{2}{3}\right]\right.
$$

\section{MODELING INDUCTION MOTOR LOSS}

Main power loss in induction machines are related to magnetic core and windings, characterizing energy conversion efficiency in motor. Overall, copper and core losses of induction motors are expressed by Equation. (5).

$$
\begin{aligned}
& P_{c u}=3\left(R_{s} \cdot i_{a s}^{2}+R_{r} \cdot i_{a r}^{2}\right) \\
& P_{\text {core }}=\left(K_{h} \cdot w_{e}+K_{e} \cdot w_{e}^{2}\right) \lambda_{m}^{2}
\end{aligned}
$$

Where, $\lambda_{m}$ is magnetizing linkage flux, $\omega_{e}$ is stator rotating angle, $K_{e}$ and $K_{h}$ are coefficients of Eddy and Hysteresis losses in motor core, respectively. Core loss is usually modeled by a resistor, $R_{f e}$, in single phase equivalent circuit of motor in steady state. Although this resistor is changed by the change in drive frequency for various speeds, this frequency variation is not high enough to worsen $R_{f e}$ accuracy for modeling in drive [20].

\section{MAGNETIZING SATURATION EFFECT ON TORQUE AND POWER LOSS}

Magnetizing saturation in induction motors greatly influence motor drive. Among the most important effects one can mention the followings:

a. Effect of torque-current rate (T/A)

b. Effect of efficiency and motor loss

c. Operational limitations on torque and linearity of motor

d. Variation of motor parameters

High current is required in order to produce high magnetizing flux. Measurements indicate that twice as much as nominal magnetizing current is needed to generate flux level of 1.3-1.4 times the nominal value. These high reactive currents affect drive and supply system performance. For a specific ratio between currents of d-q axis, maximum torque per current is obtained for the drive. This phenomenon is increased in the presence of magnetizing saturation. That is, higher currents are needed to reach maximum T/A [21]. For

Induction Motor Drive Design based on Efficiency Optimization ... (Farshid Abdolahnejad Baroogh) 
example, with $\frac{i_{d q s}^{e}}{\sqrt{2}}=i_{d s}^{e}=i_{q s}^{e}$, maximum T/A is produced. While, considering magnetizing saturation phenomenon leads to a higher value. That is, higher currents and, in turn, higher power losses for converter and motor. Figure (3) depicts torque-current-saturation percentage of core for a typical IFOC drive.

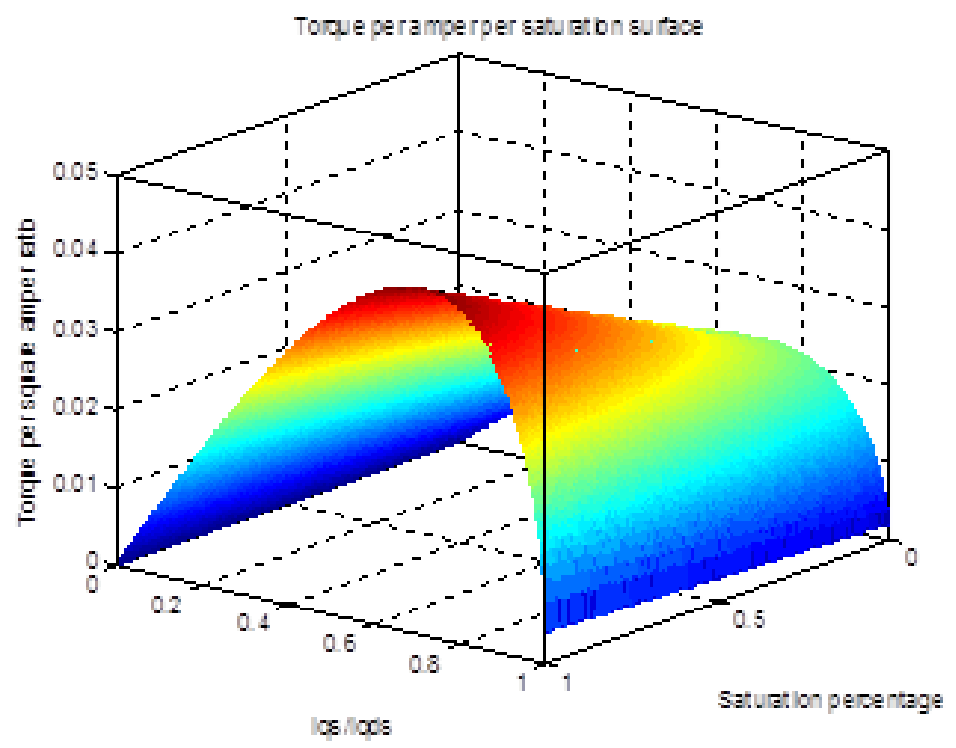

Figure 3. Typical T/A Coordinates for an Induction Motor

As seen in Figure (3), in full saturation condition, motors produce the maximum torque per square of current rate. Thus, by decreasing flux level, this rate is also reduced, pulling out machine form optimal dynamic operation area. Maximizing torque per current rate in saturation area is an issue considered in economical design of electrical machines. T/A rate can be, totally, described as the motor dynamic robust operation.

\section{DRIVE FLUX LEVEL SELECTION}

Selection of proper flux level is the most important aspect of minimization of induction motor drive loss. Flux reduction disadvantages can be: stator frequency rise when flux is decreased for a load with defined torque and speed, increased sensitivity of motor with respect to load disturbance, relatively devastated dynamic operation of drive.

Due to economic considerations, induction motors are designed in a way to be in saturation condition magnetically when they work in nominal load. In these conditions, not only maximum magnetic capacity of motors are achieved, but also core and copper losses are equal, meaning that the efficiency is maximum. In previous section, the effect of magnetic saturation is examined for T/A rate. With the decrease in motor flux level, motor will deviate from magnetic saturation area to reduce power losses. Thus, magnetic saturation is not considered when optimal motor loss operation-dynamic calculation is accomplished.

Drive losses are depending on the level of flux only in two parts of motor loss and converter loss. Drive size is important in loss division between motor and converter. The less the drive size (low power), the more the contribution of motor in drive loss. Increasing drive size results in increased converter share in power loss. In many prior research works, it was observed that only motor loss is considered as drive loss. In fact, such approximation in small drives, low power, can be acceptable; however, it leads to tolerance in drive flux level. This tolerance is observed as higher selected flux than the level in which optimal operation of motor occurs in terms of efficiency and power loss. This issue has also positive effect. Highly selected optimal flux level means increased torque level and more robust drive respect to load disturbances. 


\section{MODELING DRIVE LOSS}

As previously mentioned, drive losses are divided into five components: rectifier conduction loss, inverter conduction loss, inverter switching loss, motor copper loss and motor magnetic core loss. These components which are directly/indirectly related to drive flux level, stator current level, comprise approximately $99 \%$ of drive losses.

For standard converter, as seen in Figure (2), power losses are based on Equation. (8).

$$
\begin{aligned}
& P_{c o n v}=P_{i n v}^{c}+P_{i n v}^{s w}+P_{r a c t}^{c} \\
& P_{c o n v}=\frac{3}{\pi}\left(2 \cdot i_{s w} \cdot V_{c e}+\frac{\pi}{2} \cdot i_{s w}^{2} \cdot R_{d i f f}\right)+\frac{6 f_{s w} \cdot E_{s w} \cdot i_{s w}}{\pi}+\frac{3}{\pi}\left(V_{f} \cdot i_{s w}\left[1-\frac{\pi}{4}\right]+R_{d i f \cdot}^{d} \cdot i_{s w}^{2}\left[\frac{\pi}{4}-\frac{2}{3}\right]\right)
\end{aligned}
$$

First it should be noted that as harmonic losses related to motor and converter are ignored, thus no harmonic contents are available in drive. Even if there exist any harmonics, they will be filtered by harmonic filters. Rectifying process is a process in which energy conversion is done from AC to DC form. In practice, in a given condition, power flowing may be reversed. In this case, circuit will operate in inversed sate. Thus the circuit is capable of energy conversion in both sides. Considering fixed current of dc bus, zero output harmonics for inverter and the fact that modulation index of voltage source inverter is not changed due to constant voltage of motor stator, current flowing through all-controlled inverter's semiconductors with any desired modulation will be equal to line commutation rectifying diodes' current. In fact, mentioned conditions nullify the modulation effects and mean current through each semiconductor is considered equal to the current of rectifying diodes with lone commutation. Diodes' current in three-phase full-wave rectifier of line commutation is one-third of input first phase line current [22].

In order to find dc-link current, switching function concept with modulation can be utilized. When switching function is used, based on Eq. (9), motor current is related to dc-link current using a timedependent function which is in Fourier expansion form. Since drive harmonics are ignored, thus this time function known as switching function will be only in sinusoidal form.

$$
\begin{aligned}
& f_{a}(t)=\sum_{n=1}^{\infty} k_{n} \cos \left(n w_{e} t+v_{n}\right) \stackrel{n o \text { harmonics }}{\longrightarrow} f_{a}(t)^{1 t h}=k_{1} \cos \left(w_{e} t+v_{1}\right) \\
& i_{a s}(t)=I_{d c} \cdot f_{a}(t)^{1 t h} \\
& f_{b}(t)=\sum_{n=1}^{\infty} k_{n} \cos \left(n w_{e} t+v_{n}-\frac{2 \pi}{3}\right) \stackrel{\text { no harmonics }}{\longrightarrow} f_{b}(t)^{1 t h}=k_{1} \cos \left(w_{e} t+v_{1}-\frac{2 \pi}{3}\right) \\
& i_{b s}(t)=I_{d c} \cdot f_{b}(t)^{1 t h} \\
& f_{c}(t)=\sum_{n=1}^{\infty} k_{n} \cos \left(n w_{e} t+v_{n}+\frac{2 \pi}{3}\right) \stackrel{\text { no harmonics }}{\longrightarrow} f c(t)^{1 t h}=k_{1} \cos \left(w_{e} t+v_{1}+\frac{2 \pi}{3}\right) \\
& , i_{c s}(t)=I_{d c} \cdot f_{c}(t)^{1 t h}
\end{aligned}
$$

In fact, switching functions can be found in time-independent fashion using reference machine transformation.

$$
\left[\begin{array}{l}
f_{a}(t)^{1 t h} \\
f_{b}(t)^{1 t h} \\
f_{c}(t)^{1 t h}
\end{array}\right]=P\left[\begin{array}{l}
f_{q}^{1 t h} \\
f_{d}^{1 t h} \\
f_{0}^{1 t h}
\end{array}\right], p=\text { referenceframe matrix }
$$



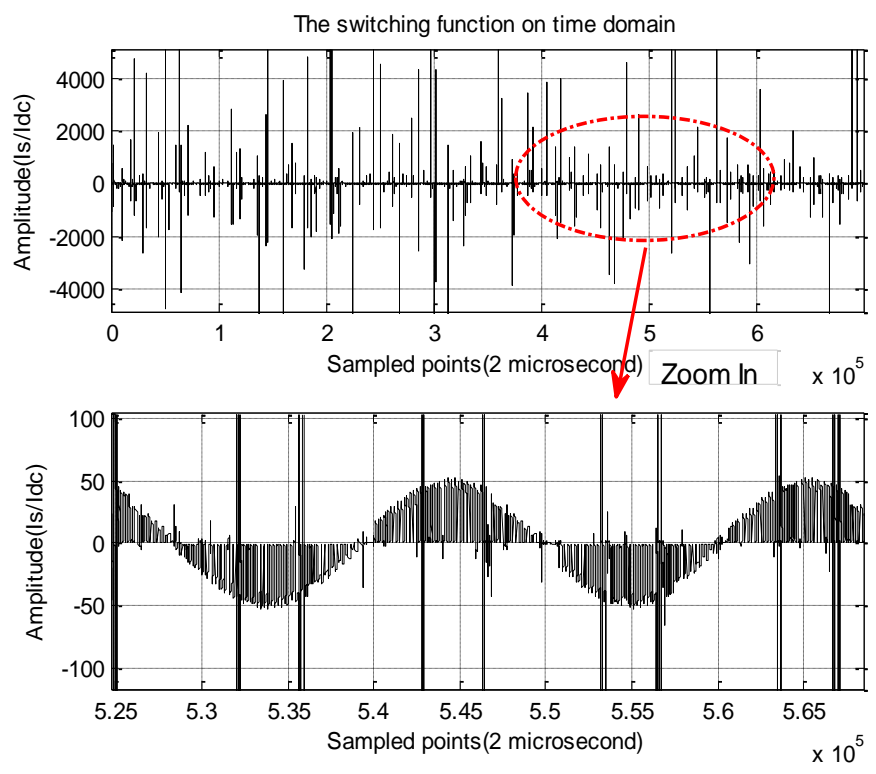

Figure 4. Switching Function of Voltage Source Inverter Connected to Induction Motor

High amplitude pulses are also seen in Figure (4). These pulses are appeared as a result of modulation which can be eliminated using capacitive-inductive filters in dc-bus.

One can use modulation index principle instead of switching function. Modulation index is defined as Eq. (11).

$$
m=\frac{A m p_{a c}^{a t h}}{\sqrt{2} A m p_{d c}}
$$

Amp is voltage or current amplitude of output modulated wave. Dc-link wave amplitude is obtained replacing modulation index and amplitude of first component of stator wave. This technique is of special advantageous when current source inverters are used in the drive.

Figure (5) illustrates power loss diagram of a typical converter as a function of first component of converter output current.

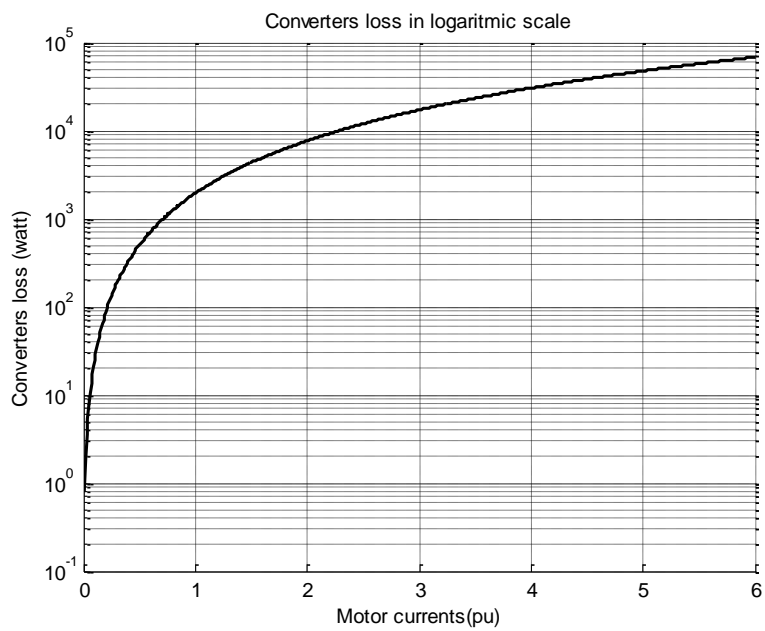

Figure 5. Power Loss Diagram of a Typical Converter as Function of First Component of Motor 
As seen in Figure 5, motor loss is increased sharply around nominal current. However, in higher currents, this experiences extreme decrease. This reduction is of special advantage in starting condition and or in non-nominal speeds because, in this condition, currents are more than nominal values.

Motor power loss components are obtained using single-phase equivalent circuit of motor. Overall, motor loss can be rewritten as Equation. (12).

$$
P^{m o t}=P_{c u}+P_{f e}=3\left(R_{s} \cdot i_{a s}^{2}+R_{r} \cdot i_{a r}^{2}\right)+f\left(w_{e}, L\right) i_{a s}
$$

$f\left(\omega_{e}, L\right)$ is a function of stator frequency and magnetizing inductance which are, in many works reported in literature, modeled by fixed resistor of $R_{f e}$ and $R_{c}$ [24].

Core loss is rewritten as Eq. (13) using single phase equivalent circuit in steady state shown in Figure (6).

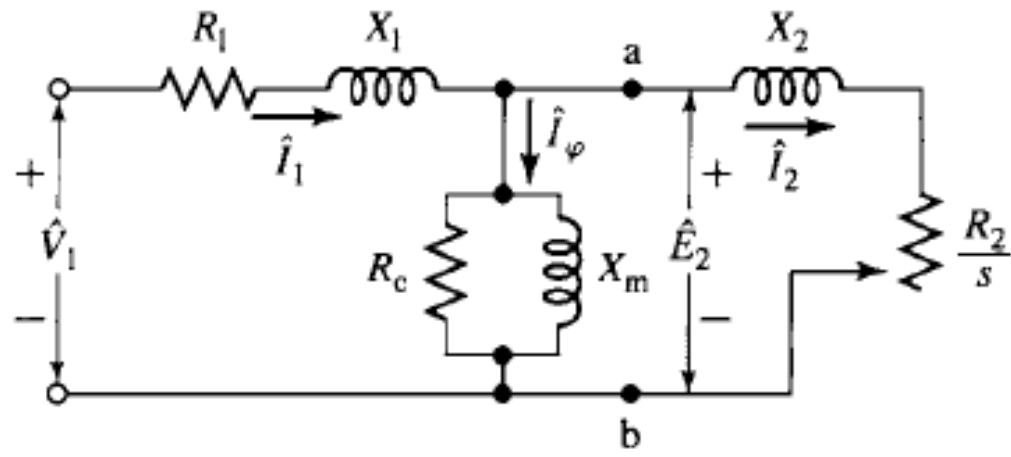

Figure 6. Single Phase Equivalent Circuit of Motor in Steady State [24]

$$
P_{f e}=3\left(\frac{\left(V_{1}-I_{1} Z\right)^{2}}{R_{c}}\right), Z=\sqrt{R_{1}^{2}+\left(w_{e} L_{1}\right)^{2}}
$$

Model (15) shows induction motor drive loss.

$$
\begin{aligned}
& P^{\text {Drive }}=3\left[\left(R_{1} \cdot i_{1}^{2}+R_{2} \cdot i_{2}^{2}\right)++\left(\frac{\left(v-I_{1} Z\right)^{2}}{R_{1}}\right)\right]+\left[\frac{3}{\pi}\left(2 \cdot V_{c e}+V_{f}\left[1-\frac{\pi}{4}\right]+2 f_{s w} \cdot E_{s w}\right)\right. \\
& \left.\left.\frac{3}{\pi}\left(\frac{\pi}{2} R_{\text {diff }}+R_{\text {diff }}^{d}\left[\frac{\pi}{4}-\frac{2}{3}\right)\right]\right) \frac{i_{1}}{3 f_{a}(t)}\right] \frac{i_{1}}{3 f_{a}(t)}
\end{aligned}
$$

Each drives of induction motors for tracking torque and command speed needs special requirement. For example, for a typical IFOC drive based on rotor flux, requirements should be prepared by Eq. (15).

$$
\left\{\begin{array}{l}
L_{r} i_{q r}^{e}+L_{m} i_{q s}^{e}=\lambda_{q r}^{e}=0 \stackrel{\text { yields }}{\longrightarrow} i_{q r}^{e}=\frac{-L_{m} i_{q s}^{e}}{L_{r}} \\
R_{r} i_{d r}^{e}-\left(w_{e}-w_{r}\right) \lambda_{q r}^{e}+\frac{d \lambda_{d r}^{e}}{d t}=V_{d r}^{e}=0 \stackrel{\text { After transientsyields }}{\longrightarrow} i_{d r}^{e}=0 \\
R_{r} i_{q r}^{e}+\left(w_{e}-w_{r}\right) \lambda_{d r}^{e}+\frac{d \lambda_{q r}^{e}}{d t}=V_{q r}^{e}=0 \stackrel{\text { After transientsyields }}{\longrightarrow} i_{d s}^{e}=\frac{R_{r} i_{q r}^{e}}{L_{m}\left(w_{e}-w_{r}\right)}
\end{array}\right.
$$

According to condition (15) and synchronous reference machine in which q-axis phasor is equal to phase- $a$, drive loss relation is rewritten as Equation. (16). 
$P^{\text {Drive }}=P^{\text {mot }}+P^{\text {conv }}$

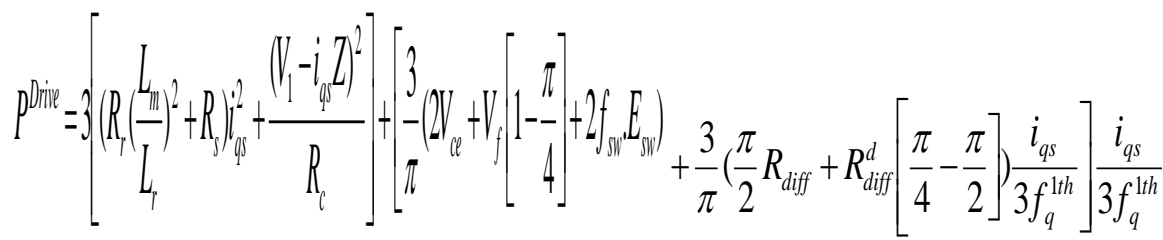

Using above relation, minimum loss value is obtained by Equation. (18).

$$
\begin{aligned}
& \frac{\partial p^{\text {Drive }}}{\partial i_{q s}}=0 \\
& i_{q s}^{e \min }=\left[\frac{6 V_{1} \cdot Z \cdot \frac{3}{\pi}\left(2 V_{c e}+V_{f}\left[1-\frac{\pi}{4}\right]+2 f_{s w} \cdot E_{s w}\right.}{6 f_{q}^{1 t h}}\right]
\end{aligned}
$$

Figure 7. Shows Equation. (18-2) in Terms of Stator Frequency Variation or Motor Speed

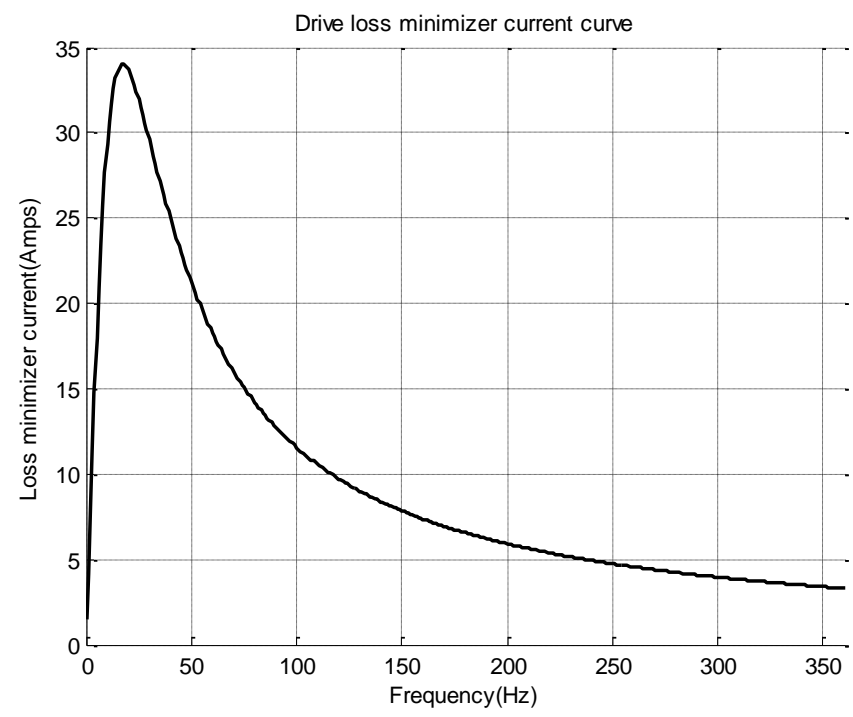

Figure 7. Value of Equation. (18-2) in Terms of Stator Frequency Variation

\section{CONTROL STRATEGY BASED ON MODEL OF EQ. (17)}

In this section, validity of previous sections is examined illustratively. An IFOC drive is constructed for this purpose. Characteristics of converter and motor are given in APPENDIX. Eq. (17) along with induction motor torque in vector drives' algorithm [24-26] are considered as a reference for selecting optimal motor flux in order to minimize drive loss. In fact, based on Figure (8), additional control block, shown in red color, is added to the drive system, allowing the driver to select reference flux level for power loss control. 
Reference flux should be changed dynamically through calculated current for stator, Eqs. (16) and (17), based on drive loading condition and for the purpose of minimizing total drive loss.
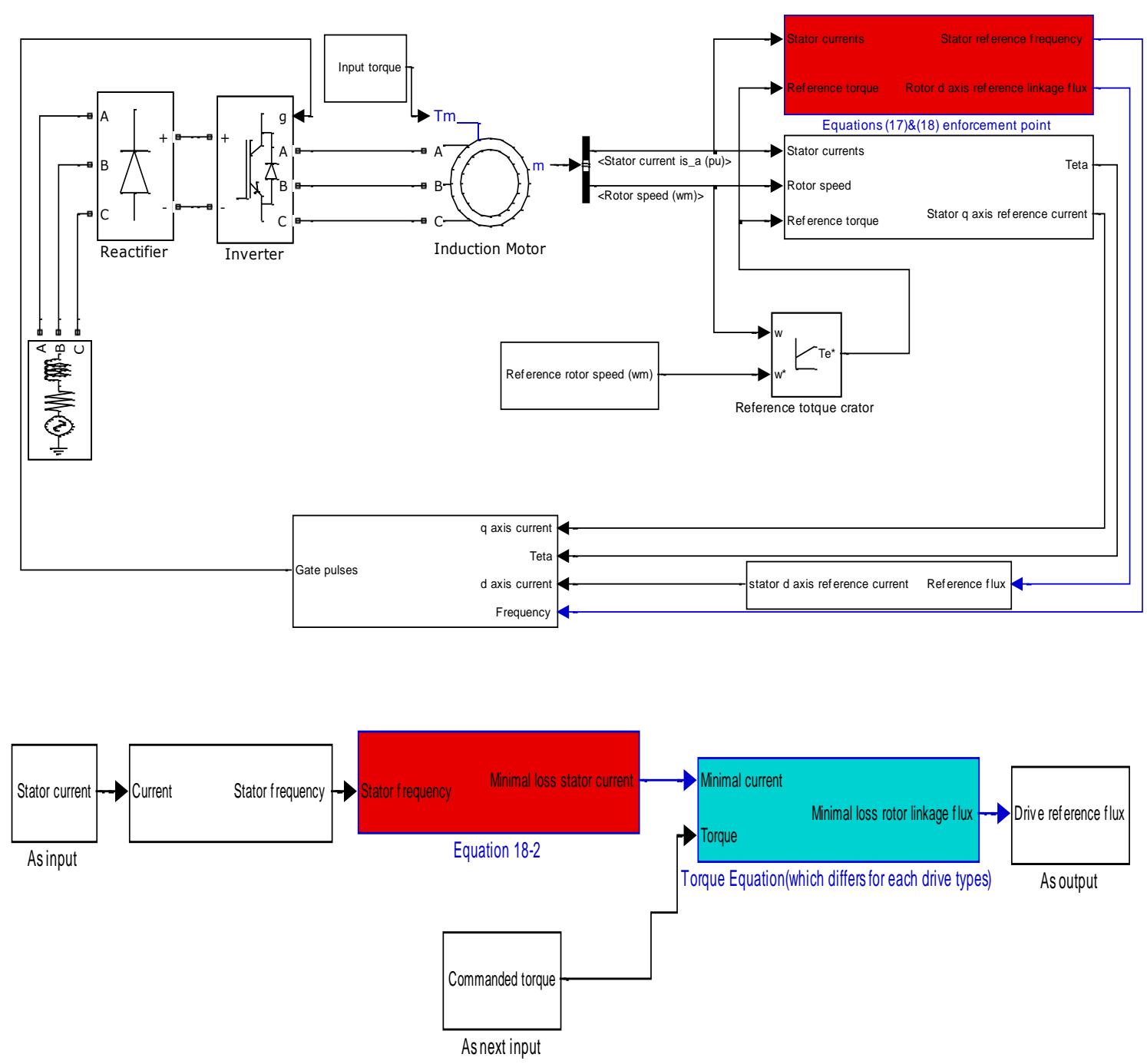

Figure 8. Block Diagram of Power Loss Control System for Induction Motor IFOC's Drive With Details of Block Containing Drive Loss Model

Red block in figure 8 is additional block containing drive loss model for which all kinds of induction motor's drives should be added proportional to drive type for minimization purposes.

Figure 9 illustrates rotor flux level selected by loss control system proportional to load decrease. As it can be seen, loss control system reduces flux level for loss minimization purpose. However, slowness of control system can be tuned by a PID controller. In general, since motor has high power, $\tau_{r}=\frac{L_{r}}{R_{r}}$ is such that the motor is inherently slow. In literature [1, 5, 12-14, 25, 26], if base was real-time control, the use of controller would be impossible for loss control system because look-up table or soft computing techniques are used. For small size drives, fast transient response can be also achieved without controller. In Figure (9), motor operates in nominal load and saturation condition prior to $\mathrm{t}=4 \mathrm{sec}$. When load decreases by half, drive reference flux nominal value reduces sharply. 


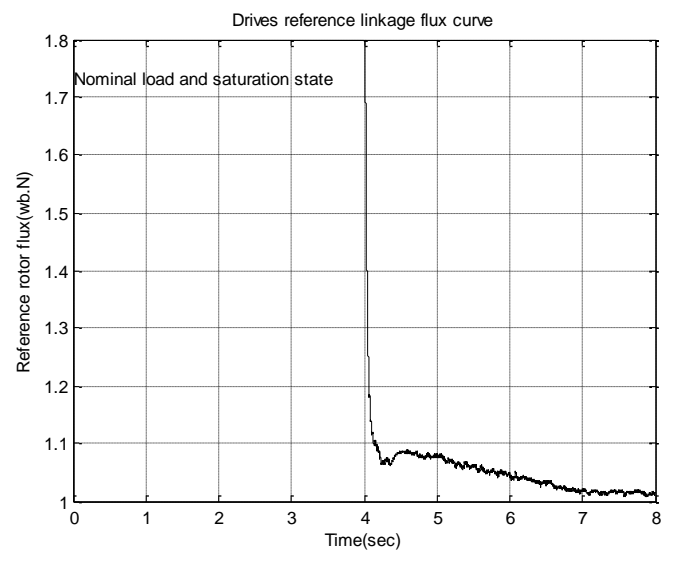

Figure 9. Rotor Flux Level

However, drive loss exhibits a more complicated behavior. Figure (10-1) shows drive loss cycle from transient to normal state. Motor current increases enormously in start-up even up to 6 times of nominal value. Current reduction leads to power loss decrease such that minimum power loss is obtained in operating point current. Curve arc is where the minimum value of drive loss occurs. Mechanical load reduction results in power loss shift on power loss cycle arc. Figure (10-2) illustrates power loss reduction by flux level control system. After $\mathrm{t}=4 \mathrm{sec}$ when mechanical load decreases to half of nominal value, power loss decreases steadily. This decreasing slop can be increased using proper controller.

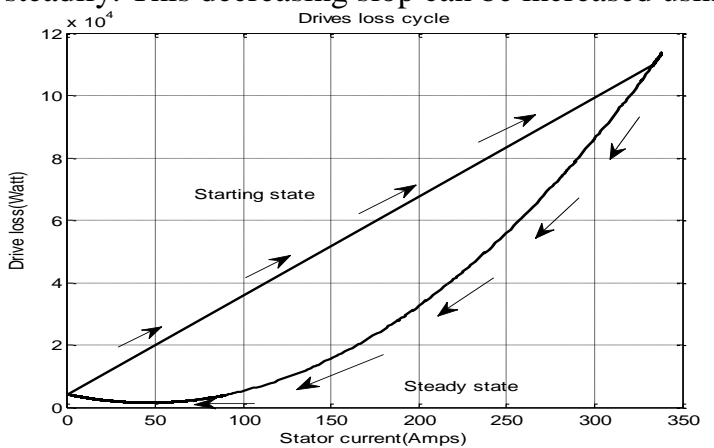

$(10-1)$

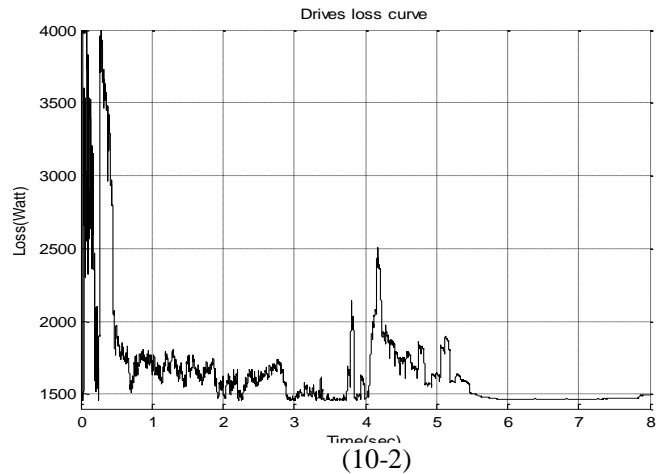

$(10-2)$

Figure 10. Typical IFOC drive power loss of induction motor. (1) Drive loss cycle. (2) Drive loss value

Figure 11. Depicts rms value of stator current in two proposed and conventional strategy of drive. As seen, remarkable variations are observed.

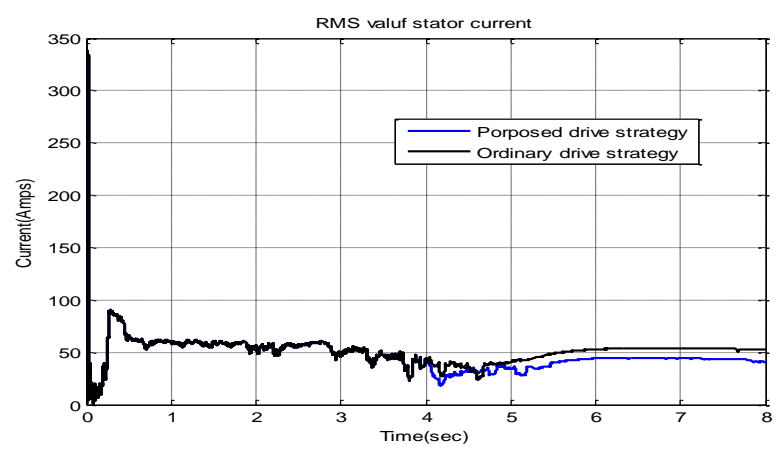

Figure 11. Typical RMS Value of Stator Current 
Robustness of power loss control system can be examined through periodic loads. Periodic loads are the extreme load in different electrical drives. In some cases, these loads can even result in drive instability and power off. Figure (12) illustrates power loss control behavior for normal reduction in mechanical load of drive and impulse load on main parameters of induction motor. Figure (12-1) shows stator current for various mechanical load conditions. Frequency variations are obvious in Figure (8). Figure (8) not only depicts transient states' effects on drive stator frequency, but also gives main feature of power loss control system, i.e. stator current reduction. Depending on drive operational condition, stator frequency is changed from start-up to steady state, and from steady to transient state, and again from transient to steady state. Figure (122) shows speed curves in two load modes. In ideal and high flux conditions, any load changes from no-load to full-load states should not make any speed change. However, motor sensitivity respect to input mechanical change is increased due to flux level reduction. In Figure (12-2), partial speed changes are observed in this curve. Figure (12-3) depicts output torque waveforms. Comparison between tracked waveform by drive and generated command waveform within drive without considering distortions resulting from modulation effect reveals that performance of drive and power loss control system is accurate. Modulation and linearity effect for generating motor drive algorithm is the most important torque disturbance. However, mechanical load conversion system suppresses the distortions greatly. The drive has a proper accuracy for tracking torque command proportional to overall power loss level of converter and machine.
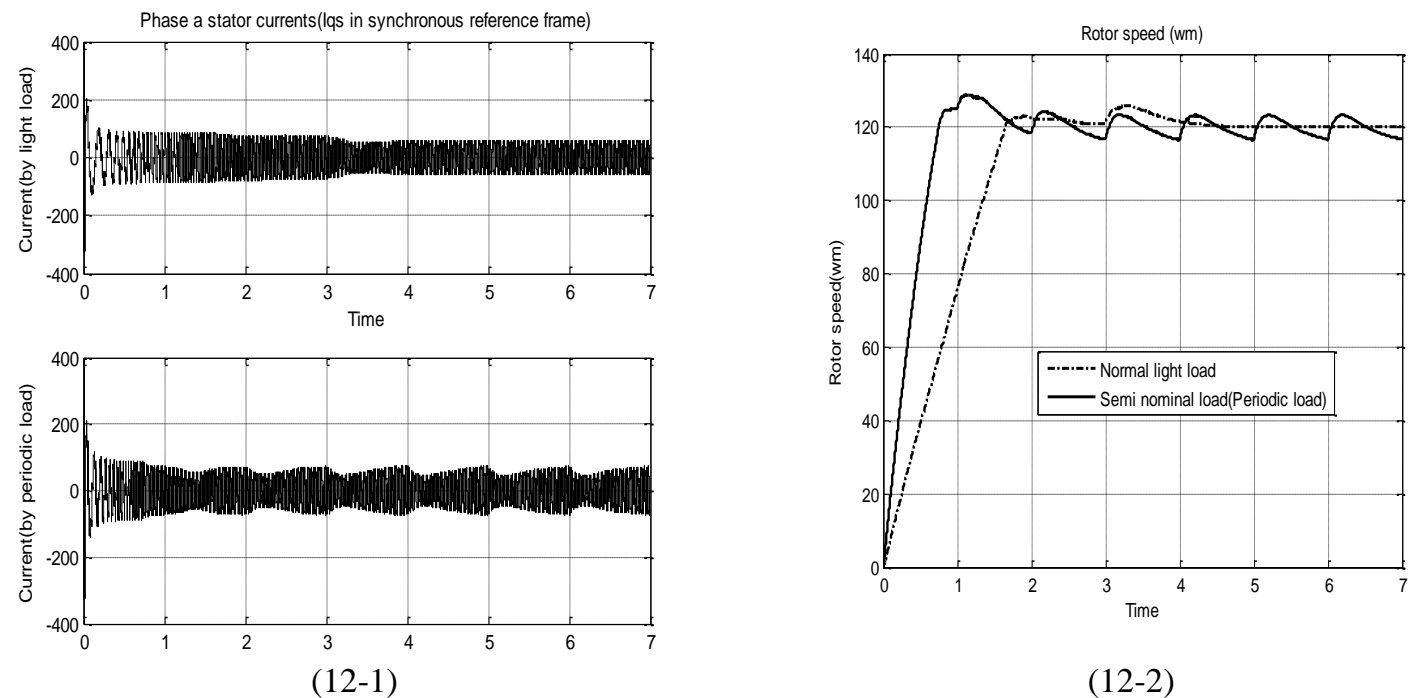

$(12-2)$

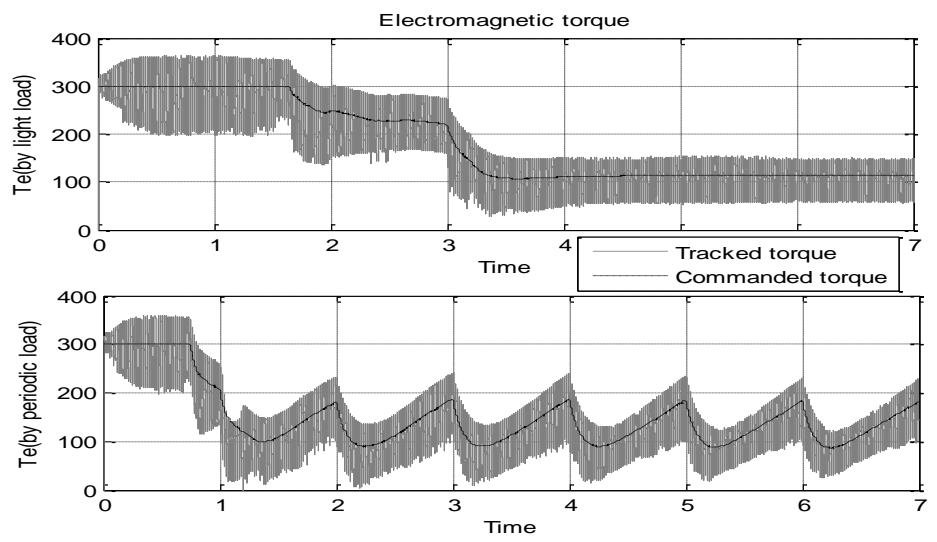

$(12-3)$

Figure 12. Power Loss Control System Effect of Normal Reduction in Drive Mechanical Load and Impulse Load on Induction Motor Parameters. (1) Stator Current, (2) Mechanical Speed, (3) Electromagnetic Torque 


\section{CONCLUSION}

In this paper, a real-time technique with reduced computation and high accuracy for minimization or optimization of induction motor drive power loss is proposed with desired power. Drive power loss is highly dependent on motor power loss. In many reported works in literature, motor losses are considered as drive overall power loss while converter loss is ignored. In high powers, converter power loss is increased sharply, resulting in deviation of power loss control system coordinates from optimum point. Thus, using an exact model of this paper for the drive can be advantageous. Of course, previous models include converter loss and considered for drive power loss were very complicated. Using those models for real-time control of complicated drives with high power, including non-linear control drives of induction motor are practically impossible. Therefore, using proposed model in this paper for such drives might be ideal and even necessary. In addition, due to existence of complicated loads operating periodically, the use of prior complex models for optimization of power loss may be impossible. Because, previous techniques are either inaccurate or need complicated models for increasing accuracy. Thus, periodic load can nullify drive stator stability, making it to be unstable. The proposed model, in this paper, resolves this issue. Moreover, in addition to robustness of power loss control system, controller design is possible in order to improve time response and reduction of digital calculation. Despite previous models, this model can be implemented on various induction motor drives such as scalar, vector and non-linear types. This model has also no power limitation.

\section{Appendix}

$$
\begin{aligned}
& p_{\text {mech }=50 h p, V_{L-L}}=460, f_{e}=60 \mathrm{HZ}, w_{r}=120 \mathrm{rad} / \mathrm{s}, f_{q}=31.176 P_{\text {in }}=37.3 \mathrm{KVA} \\
& R_{s}=0.087 \Omega, R_{r}^{\prime}=0.228 \Omega, L_{s}=L_{r}^{\prime}=0.0355 \mathrm{H}, L_{m}=0.0335 \text { Pole pair }=2, R_{\text {diff }}^{d}=R_{\text {diff }}^{I G B T}=1 \mathrm{~m} \Omega \\
& V_{c e}=V_{f}=0.8 v, E_{s w} \approx 0, R_{f e}=50 \Omega
\end{aligned}
$$

\section{REFERENCES}

[1] Gilberto C.D souse, Bimal k. bose, John G. Cleland, "Fuzzy logic based on-line efficiency optimization control of an indirect vector-controlled induction motor drive," IEEE Transaction on Industrial Electronics, vol. 42, issue 2, April 1995.

[2] Ian T. Wallace, Donald W. Novotny, Robert D. Lorenz, epakraj M. Divan, "Increasing The Dynamic Torque Per Ampere Capability Of Induction Machines," IEEE Transactions on Industry Applications, vol.30, issue.1, January 1994.

[3] Iordanis kioskeirdis, Nikos margaris, "Loss minimization in induction motor adjustable-speed drives," IEEE Transaction on Industrial Electronics, vol.43, issue 1, Februarey 1996.

[4] Sheng-Ming Yang, Feng-Chieh Lin, "Loss-minimization control of vector-controlled induction motor drives," Power Electronics and Drive Systems, 2001. Proceedings, 4th IEEE International Conference, vol.1, pp. 182 - 187, October 2001.

[5] E Abrahamsen, "Energy optimal control of induction motor drives," Ph.D. thesis, Aalborg University, Denmark, ISBN 87-89179-26-9, Feb. 2000.

[6] E Ramprasath, "Modelling and analysis of induction motor using LabVIEW," International Journal of Power Electronics and Drive System, vol.5, no.3, pp.344-354, February 2015.

[7] Abrahamsen F., Blaabjerg F., Pedersen J.K., Grabowski P.Z., Thogersen P., "On the energy optimized control of standard and high-efficiency induction motors in CT and HVAC applications," IEEE Transactions on Industry Applications, pp.822 - 831, vol. 34 , issue: 4,1998 .

[8] Irwan Y., Irwanto M., Safwati I., Gomesh N., Ezzani M., Risnider C.B., "Improvement of induction machine performance using power factor correction," 2011 International Conference on electrical, Control and Computer engineering (INECCE), pp. 472-476, 21-22 June 2011, Pahang, China.

Hemavathy K., Pappa N. "Comparison of indirect vector control and direct torque control applied to induction motor drive," 2014 International Conference on advanced Communication control and Computing Technologies (ICACCCT), pp. 192-197, 8-19 May 2014, Ramanathapuram.

[9] Talukader P., Soori P.K., Aranjo B., "Speed control of induction motor drive using universal controller," 2012 IEEE International Power Engineering and Optimization Conference (PEDCO), pp. 6-7, June 2012, Melaka, Malaysia.

[10] Pragasen Pillay, Ray Nolan, Towhidul Haque, "Application of Genetic Algorithms to Motor Parameter Determination for Transient Torque Calculations," IEEE Transactions on Industry Applications, vol.33, no.5, September/October 1997. 
[11] Bimal K.Bose , Nitin R.Patel and Kaushik Rajashekara, “A Neuro-Fuzzy Based On-Line Efficiency Optimization Control of a Stator Flux-Oriented Direct Vector-Controlled Induction Motor Drive," IEEE Transaction On Industrial Electronics, vol. 44 , no. 2 , April 1997.

[12] Chelliah, T.R.; Yadav, J.G.; Srivastava, S.P.; Agarwal, P., "Optimal energy control of induction motor by hybridization of loss model controller based on Particle Swarm Optimization and search controller," World Congress on Nature\&Biologically Inspired Computing, pp. 1178 - 1183, 2009.

[13] Ebrahim, O.S.; Badr, M.A.; Elgendy, A.S.; Jain, P.K., "ANN-Based Optimal Energy Control of Induction Motor Drive in Pumping Applications," IEEE Transactions on Energy Conversion, pp.652 - 660, vol.25, Issue 3, 2010.

[14] Uddin, M.N., Sang Woo Nam, "Development of a Nonlinear and Model-Based Online Loss Minimization Control of an IM Drive," IEEE Transactions on Energy Conversion,, vol. 23 , issue 4, pp.1015 - 1024, 2008.

[15] Alex Borisevich, "Numerical method for power losses minimization of vector-controlled induction motor," International Journal of Power Electronics and Drive Systems, vol.6, no.3, pp. 486-497, September 2015.

[16] Kioskeridis, I.; Margaris, N., "Loss minimization in scalar-controlled induction motor drives with search controllers ," IEEE Transactions on Power Electronics, vol.11, issue 2, pp. 213 - 220, 1996.

[17] Zengcai Qu; Ranta, M.; Hinkkanen, M.; Luomi, J., "Loss-Minimizing Flux Level Control of Induction Motor Drives ,"IEEE Transactions on Industry Applications,, Volume: 48 , Issue: 3, pp.952 - 961,2012.

[18] A. E. Fitzgerald, Charles Kingsley, Jr. and Stephen D. Umans , "Electric Machinery", Sixth Edition, McGraw-Hill Higher Education, ISBN 0-07-366009-4--ISBN 0-07-112193-5.

[19] S. Khomfoi, V.Kinnares and P.Viriya, "Investigation into core losses due to Harmonic Voltages in PWM fed Induction Motors," IEEE 1999 International Conference on power electronics and Drive systems, July 1999, Hong Kong.

[20] Wallace I.T., Novotny D.W., Lorenz R.D., Divan, D.M., "Verification of enhanced dynamic torque per ampere capability in saturated induction machines," IEEE Transactions on Industry Applications, pp. 1193 - 1201, vol.30, issue 5,1994.

[21] J. David Irwin, Timothy L. Skvarenina, “The power electronics handbook,” ISBN 0-8493-7336-0, TK7881.15 .P673 2001, CRC Press LLC.

[22] Rasmus K. Ursem, Pierr'e Vadstrup, "Parameter Identification of Induction Motors using Stochastic Optimization Algorithms," The 2003 Congress on Evolutionary Computation, vol.2 ,pp. 790 - 796, 8-12 December 2003.

[23] Blimal K. Bose, "Power Electronics and Variable Frequency Drives," ISBN 0-7803-1084-5, IEEE Order Number: PC4382, The Institute of Electrical and Electronics Engineers Inc, 1997.

[24] Uddin M.N.,Sang Woo Nam, "New Online Loss-Minimization-Based Control of an Induction Motor Drive," IEEE Transactions on Power Electronics, , vol.23 , issue 2, pp. 926 - 933, 2008.

[25] Xu, X.; Novotny, D.W., "Selecting the flux reference for induction machine drives in the field weakening region," Conference Record of the 1991 IEEE Industry Applications Society Annual Meeting, pp. 361 - 367, vol.1,1991.

[26] www.semicron.com/Products/IGBT/ SKM 400 GB 124D. 